\title{
Covid-19: protecting patients in hospital for neurorehabilitation and their therapists
}

\author{
Jonathan Mamo consultant in neurorehabilitation, Beenish Feroz specialist registrar, Sazan Mahmood \\ specialist registrar
}

Department of Neurorehabilitation, Royal Berkshire Hospital, Reading RG1 5AN, UK

One of the unforeseen challenges for NHS hospitals during the covid-19 epidemic ${ }^{1}$ is ensuring the safety of patients who would normally be residing in the hospital at this time of year, such as those undergoing neurorehabilitation. A large proportion of these patients are over the age of 60 , making them "sitting ducks" for acquiring covid-19 if a patient with the infection was placed in the immediate area.

Our department is generally populated with a mixed age group of patients with numerous multiple comorbidities, which places them in a very risky situation. Immediate departmental recommendations have been put in place to safeguard these patients, including limitation of the number of visitors, higher thresholds for home visits and ward leave, limitations on social dining, and therapy sessions limited to the immediate bed space until newly admitted patients experience sufficient isolation.
The national shortage of personal protective equipment is disappointing and will undoubtedly have major consequences. Therapists are at risk of contracting covid-19 on the basis of contact time. We need an urgent national guideline on how continued access to rehabilitation could be achieved for a high risk group at a time when the NHS could do with the improved bed flow.

Competing interests: None declared.

1 Willan J, King AJ, Jeffery K, Bienz N. Challenges for NHS hospitals during covid-19 epidemic. BMJ 2020;368:m1117. 10.1136/bmj.m1117 32198166

Published by the BMJ Publishing Group Limited. For permission to use (where not already granted under a licence) please go to http://group.bmj.com/group/rights-licensing/ permissions 